


\section{DUAS ABORDAGENS SOBRE O ESCRAVISMO E O COMÉRCIO DE ESCRAVOS EM ANGOLA}

CANDIDO, Mariana P. An African Slaving Port and the Atlantic World: Benguela and its Hinterland. Cambridge: Cambridge University Press, 2013. 366 p.

SILVA, Daniel B. Domingues da. The Atlantic Slave Trade from West Central Africa, 1780-1867. Cambridge: Cambridge University Press, 2017. 231 p.

O comércio transatlântico de escravos é um campo de estudos já bastante desenvolvido, e de crescente interesse, pelo menos nas últimas três décadas. Um número significativo de pesquisadores tem enfatizado o papel dos comerciantes de escravos do Atlântico Norte no tráfico de seres humanos, do século XVII ao XIX, bem como o impacto da escravização e exportação de cativos sobre as sociedades africanas. No entanto, o tráfico no Atlântico Sul, principalmente entre o Brasil e a África Central - nomeadamente Congo e Angola - atraiu menos atenção do que merece, dado que quase a metade dos escravos deportados através do Atlântico para as Américas veio daquela região, nos cerca de cem anos entre meados do século XVIII até a abolição do tráfico escravista, em meados do século seguinte.

Depois das obras seminais de David Birmingham, Jan Vansina, Bea- trix Heintze, John Thornton e Joseph Miller, uma nova geração de estudiosos está revisitando a escravidão e o tráfico de escravos de Angola, trazendo novas abordagens e informações sobre o assunto. ${ }^{1}$ Os livros de Mariana P. Candido e Daniel B. Domingues da Silva, aqui resenhados, são bons exemplos da nova safra

1 David Birmingham, Trade and Conflict in Angola: The Mbundu and Their Neighbours Under the Influence of the Portuguese, 1483-1790, Oxford: Clarendon Press, 1966; Jan Vansina, Kingdoms of the Savanna, Madison: University of Wisconsin Press, 1966; Beatrix Heintze, Angola nos séculos XVI e XVII: estudos sobre fontes, métodos e história, Luanda: Kilombelombe, 2007; John K. Thornton. Africa and Africans in the Making of the Atlantic World, 1400-1680, Cambridge: Cambridge University Press, 1992; Joseph C. Miller, Way of Death: Merchant Capitalism and the Angolan Slave Trade, 1780-1830, Madison: University of Wisconsin Press, 1988. 
neste campo de estudos. ${ }^{2}$ Com pontos em comum e divergentes, ambos os autores desafiam a mesma tese da "fronteira da escravidão" (que foi totalmente elaborada por Miller, mas que pode ser rastreada nas obras antes citadas de Vansina e Birmingham e, de certo modo, em Claude Meillassoux), segundo a qual o papel da violência na produção de escravos em Angola foi substituído - após um período que podia variar de um lugar para outro - por métodos mercantis de escraavização no território sob controle dos portugueses e seus aliados; enquanto isso, as práticas de guerra e de captura como fontes de produção de escravos se tranferiram para as sociedades além desses

2 Que inclui, entre outros, Roquinaldo Ferreira, "Transforming Atlantic Slaving: Trade, Warfare and Territorial Control in Angola, 1650-1800" (Tese de Doutorado, Universidade da Califórnia em Los Angeles, 2003); Roquinaldo Ferreira, Cross-Cultural Exchange in the Atlantic World: Angola and Brazil During the Era of the Slave Trade, Nova York: Cambridge University Press, 2012; Maximiliano M. Menz, "As 'geometrias' do tráfico: o comércio metropolitano e o tráfico de escravos em Angola (17961807)", Revista de História, n. 166 (2012), pp. 185-222; José C. Curto, Álcool e escravos: o comércio luso-brasileiro de álcool em Mpinda, Luanda e Benguela durante o tráfico atlâtico de escravos (c. 1480-1830) e o seu impacto nas sociedades da África Central Ocidental, Lisboa: Vulgata, 2002. Deste mesmo autor, há vários estudos sobre a relação entre tráfico de escravos e a demografia de angola; por exemplo, J. C. Curto e Raymond R. Gervais, "A dinâmica demográfica de Luanda no contexto do tráfico de escravos do Atlântico Sul, 1781-1844", Topoi, Rio de Janeiro, v. 3, n. 4 (2002), pp. 85-138. territórios "pacificados". ${ }^{3}$ Enquanto Mariana Candido, professora da Universidade de Notre Dame (EUA), privilegia os dados qualitativos, a fim de demonstrar a difusão da violência dentro das fronteiras portuguesas de Angola, Domingues da Silva, professor na Universidade de Rice (EUA), baseia-se mais em dados quantitativos, sem desconsiderar os qualitativos, para sustentar suas descobertas.

Nos cinco capítulos do livro de Mariana Candido, centrado na região de Benguela e seu interior, a violência ganha o papel principal. A historiadora brasileira argumenta que a violência foi fundamental para moldar as transformações que a região de Benguela sofreu desde o início do século XVII, momento em que o comércio de escravos substituiu a busca por jazidas minerais como a principal atividade econômica da região. Das instituições políticas às relações sociais, bem como as identidades pessoais e coletivas, traços culturais etc., toda a sociedade foi afetada por seu envolvimento - e imersão - no tráfico de escravos. Em suas próprias palavras: "De fato, a violência é vista neste estudo como fundamental ao colonialismo e à ocupação territorial, e sua continuidade provocou a reorganização política, a reorientação econômica e alterou valores sociais

3 Além dos livros de Miller, Birmingham e Vansina indicados na nota 1 , cf. Claude Meillassoux, Antropologia da escravidão: $o$ ventre de ferro e dinheiro, Rio de Janeiro: Zahar, 1995, pp. 35-42, embora o autor tenha como foco a região sahelo-sudanesa. 
e culturais, criando novos grupos e práticas" (p. 314). Desse ponto de vista o trabalho pretende ser "uma grande reavaliação do impacto do tráfico transatlântico de escravos sobre as sociedades africanas" (p. 8).

A autora parte de uma diversidade de documentos manuscritos, como cartas régias e de funcionários portugueses no ultramar, consultados em arquivos de Portugal, Brasil e Angola, bem como de relatos coevos de viajantes, cronistas e outras fontes primárias publicadas. Como base em suas pesquisas, critica um conjunto de argumentos que vieram a prevalecer entre os principais estudiosos neste campo de estudos, acima de tudo a subestimação do impacto amplo sobre a sociedade local causado pela drenagem humana por meio do tráfico de escravos. Mesmo o processo de crioulização - isto é, a formação de uma cultura híbrida luso-africana - tem uma estreita relação com a escravidão e o tráfico de escravos e, portanto, com a violência: "o impacto do tráfico transatlântico de escravos não pode ser medido simplesmente pelo número de pessoas exportado do continente. Seus efeitos foram além da demografia, alterando estilos de vestir, a alimentação e os hábitos de beber, e permitindo a introdução de novas ideias e tecnologias" (p. 173).

Um dos debates mais duradouros sobre Angola na era da expansão ultramarina europeia refere-se à suposta existência de uma etnia a que os portugueses chamavam de Jaga. Mariana Candido aborda este assun- to no primeiro capítulo, apontando as contradições nos relatos contemporâneos sobre as características dos Jagas. Ela escreve: "Assim, ao invés de referir-se a grupo específico de pessoas em Benguela, [o termo] jaga era empregado para se referir a inimigos sem nome, cuja estrutura social e política era estranha para os portugueses. Em suma, eles apenas existiam na mente dos portugueses, incapazes de identificar diferenças entre grupos diferentes" (p. 60, cf. p. 247,250 e 317). Significa dizer que "jaga" seria uma categoria portuguesa que, ao ser empregada para identificar indivíduos que detivessem poder político sobre um território e seus habitantes no interior de Benguela, legitimava o uso da força contra eles e, assim, a produção de cativos, o que alimentava o comércio escravista.

O segundo livro, The Atlantic Slave Trade from West Central Afri$c a$, resulta da tese de doutorado de Daniel Domingues da Silva, o que explica sua concisão e brevidade de algumas de suas conclusões. Embora escorado em sólida pesquisa de arquivo (em Portugal, Grã-Bretanha, EUA e Brasil), boa parte da obra é fundamentada nos dados do Transatlantic Slave Trade Database- um banco de dados sobre os números do tráfico transatlântico de cativos $-{ }^{4}$ com o qual o autor possui grande familiaridade, pois tem contribuído

4 Cf. <www.slavevoyages.org>, acessado em 17/10/2019. 
para sua atualização. ${ }^{5} \mathrm{O}$ livro é composto por seis capítulos, dos quais pelo menos cinco são baseados, principalmente, em dados quantitativos.

No primeiro capítulo, Domingues fornece novas estimativas sobre as exportações de escravos de Angola, discriminadas por portos, e relaciona a flutuação desse comércio de escravos às tendências atlânticas na oferta e na procura por mão de obra cativa, provocadas por episódios e processos como a Revolução Industrial, a Revolução do Haiti e o da produção de commodities no Brasil, bem como os esforços britânicos para suprimir o comércio de africanos no século XIX. Ao contrário do que seria de se esperar - isto é, que o aumento na demanda por cativos teria levado ao incremento no número de cativos deportados -, ele conclui que as exportações de escravos de Angola permaneceram estáveis entre final do século XVIII e metade do XIX. Tal estabilidade dever-se-ia ao fato de que os britânicos e os franceses retiraram-se do comércio direto de escravos africanos e, mesmo que a demanda por estes estivesse em ascensão, para atendê-la os portugueses e brasileiros expandiram suas atividades para os portos ao norte de Luanda, que eram antes frequenta-

5 De fato, o autor tem sido um dos responsáveis pela gestão dessa base de dados. Ele foi o coordenador de imagens, forneceu novos dados sobre viagens negreiras e é membro da equipe que desenvolve o projeto "African origins", cf. $<\mathrm{http} / / /$ www.african-origins.org $>$, acessado em 17/10/2019. dos pelos negreiros daquelas duas nações. Assim, os luso-brasileiros não abriram novas áreas de exportação de escravos, mas aproveitaram as antigas, mais próximas ao litoral. Assim, para suprir a crescente demanda não foi preciso que a fronteira da escravidão se estendesse ao interior mais distante.

Domingues da Silva ressalta essa conclusão no que talvez seja o ponto alto de seu livro, o capítulo 3 , que trata das origens dos escravos de Angola destinados ao comércio transatlântico. A análise das "listas dos africanos emancipados [do tráfico ilegal] em Cuba e Brasil, acrescentadas aos registros de escravos feitos pelos funcionários portugueses em Angola" (p. 73) fornecem milhares de dados sobre os africanos escravizados. Esses dados permitem traçar a participação das regiões e etnias de Angola (grupos quicongo, quimbundo e umbundu) na diáspora entre 1831 e 1855 , apontando que a maioria deles veio de regiões dentro da jurisdição portuguesa mais próximas ao litoral. Fazendo isso, Domingues reforça - como Mariana Candido - a historiografia que retrata o comércio transatlântico de escravos em seu conjunto como importante fonte de crise social e demográfica na África.

O segundo capítulo diz respeito à organização comercial e, além de explicar o papel dos vários agentes comerciais em Angola - incluindo o desempenho de um dos principais, Anselmo Coutinho - e as ligações entre Angola e Brasil, avança outro argumento, qual seja: "uma avalia- 
ção da oferta de escravos do interior para a costa deve levar em consideração as estações e o calendário agrícola das populações" (p. 67). Combinando dados de embarques e precipitação pluvial, ele conclui que as exportações de escravos atingiam o pico nas estações secas, ou no período entre dois ciclos agrícolas, quer dizer, esses fatores internos à África seriam mais importantes do que a demanda por trabalho escravo na América. Mesmo que ele não forneça, neste segmento, uma explicação precisa para esta correlação, no capítulo 6 a encontramos: "As batalhas ocorriam principalmente durante as estações secas, quando homens e mulheres estavam livres do cultivo e os exércitos podiam mover-se mais facilmente pelo interior" (p. 149). De maneira semelhante, Mariana Candido enfatiza a estreita relação entre guerras, fome, secas e migração, que serviram para aumentar o número de pessoas escravizadas; mas ela argumenta, convincentemente, que a fome e a seca não podem ser vistas como fenômenos naturais: "A fome que afetava o Ndombe e outros [povos] não pode ser dissociada das ações dos agentes portugueses e das pressões do tráfico transatlântico de escravos" (p. 77).

Os perfis de idade e sexo dos escravos são abordados no capítulo 4 de Domingues da Silva, que ressalta os fatores africanos que explicariam a maior participação de homens como vítimas do tráfico de escravos. O autor afirma que "o mais provável é que as forças moldando o perfil demográfico dos escravos que deixavam a África Centro-Ocidental tivessem se originado na África mais do que na América" (p. 107). Entre essas forças, ele destaca a característica matrilinear das sociedades angolanas, o papel feminino na produção e a ameaça que representava manter soldados escravizados próximos aos seus captores. No entanto, como o autor admite, a flutuação na participação das mulheres no comércio atlântico de escravos a partir do final do século XVIII podia decorrer de que os "produtores [no Brasil] tivessem mudado suas atitudes em relação à aquisição de mulheres" (p. 105), o que ele deduz da queda na diferença média de preços entre homens e mulheres cativos no Rio de Janeiro, de 1810 a 1830 , sugerindo que a pressão inglesa pelo fim do comércio negreiro teria aumentado o valor atribuído ao papel reprodutivo das mulheres.

Neste aspecto, os livros aqui resumidos discordam, já que Mariana Candido destaca o papel ativo de agentes portugueses na promoção da escravidão e do tráfico de escravos do interior, o que ela vê como uma abordagem mais equilibrada, enquanto Domingues da Silva salienta o papel dos africanos na moldagem do padrão da escravização e do tráfico de escravos. Como destacado anteriormente, para sustentar seus argumentos, a autora privilegia os dados qualitativos, como os incidentes de escravização, por entender que os quantitativos "tendem a ocultar o fato de que aqueles números 
representam seres humanos que sofreram violência física e mental" ( $p$. 198). Esta crítica, embora me pareça que precise ser matizada, caberia a alguns momentos do livro de Daniel Domingues, nos quais ele propõe respostas a questões bastante amplas e complexas com base apenas nos números, como, por exemplo, a respeito do predomínio de indivíduos do sexo masculino entre os deportados para a América, atribuindo-o, como acima mencionado, a características das sociedades da África Centro-Ocidental. Por sua vez, Mariana Candido demonstra que diversos fenômenos relacionados à produção dos escravos na mesma região derivavam diretamente da ação dos portugueses e luso-brasileiros que lá viviam e agiam (capítulo 4), contrapondo-se, portanto, ao relevo dado à "agência" africana no tráfico de braços forçados.

Não é de surpreender que os livros de Mariana Candido e Domingues da Silva se sobreponham em alguns assuntos, como nos mecanismos de escravização. Candido, porém, não só analisa os métodos amplamente conhecidos de transformar uma pessoa livre em cativa (guerra, processo judicial, sequestro, invasões, dívidas), mas também desafia uma interpretação bastante disseminada sobre serem alguns desses métodos tidos como aquisição pacífica de escravos, a exemplo da escravização por dívida e por condenação judicial, que a autora considera parte de um sistema legal e uma ordem social violentos (capítulo 4). Domingues da Silva afirma (capítulo 6), por sua vez, que a guerra em larga escala não era a principal fonte de escravos exportados de Angola - argumentando que a maioria dos conflitos era de pequena escala -, porque as relações entre as entidades políticas da África Centro-Ocidental estavam, elas mesmas, repletas de conflitos de pequena escala, os quais teriam gerado a maioria dos cativos.

Ambos os autores, Daniel Domingues e Mariana Candido, convergem ao lançar dúvidas sobre a tese da "fronteira escravista", tentando demonstrar que a linha entre quem era e quem não era passível de ser escravizado não seria muito clara, nem era definida pela jurisdição política portuguesa. Pessoas vivendo por longos anos sob o domínio português eram, muito frequentemente, ameaçadas por escravizadores e acabavam perdendo sua liberdade por meios ilegais mal disfarçados.

Podemos dizer que o comércio transatlântico de escravos foi um dos ramos de negócio mais globalizados durante a Idade Moderna ${ }^{6}$

6 Mesmo que possa haver um ceticismo justo sobre a utilidade da abordagem da história global aplicada à história africana. Para uma visão crítica, cf. Frederick Cooper, "What Is the Concept of Globalization Good for? An African Historian's Perspective," African Affairs, v. 100, n. 399 (2001), pp. 189-213, no qual ele comenta: "uma linguagem que implica que não há nenhum recipiente, exceto o planetário, arrisca-se a definir os problemas de formas enganosas" (p. 190). Para uma visão ampla sobre trabalhos que abordam a África e a 
uma vez que envolvia pessoas e bens de quatro continentes. Este, porém, é um aspecto que recebe maior ênfase no livro de Daniel Domingues. O tipo, a origem e a circulação das mercadorias utilizadas no tráfico de escravos não são destacados na abordagem de Mariana Candido, embora ela esteja ciente do papel primordial das importações na construção da escravidão e do tráfico de escravos em Benguela (capítulo 3).

O capítulo 5 de Domingues da Silva se concentra nos "Padrões africanos de consumo", fornecendo dados sobre bens comerciais e sua participação nas importações de Angola. Como poderíamos esperar, as mercadorias europeias e asiáticas compunham a maioria das importações, diante do que uma afirmação de Domingues da Silva parece pouco clara: "Até o começo do século XIX, muitas das mercadorias utilizadas para comprar escravos eram produzidas em Portugal e no Brasil" (p. 49). No entanto, o autor fornece os principais tipos de têxteis que predominavam no comércio português de escravos, e eles não eram de origem portuguesa; em vez disso, se originavam no noroeste europeu, na Europa central e, principalmente, no leste da Índia. Suas conclusões baseiam-se nos dados hauridos nas listas de importações de Luanda, de

história mundial, cf. Leslie Witz, "Africa [Not] in World History: A Review from the South," Journal of World History, v. 27, n. 1 (2016), pp. 103-120.
1785 a 1864 , ficando demonstrada a maior parcela de têxteis da Índia frente aos europeus até 1830, quando começa o período de tráfico ilegal (1831). Só então os têxteis da Europa assumem a primeira posição. Por sua vez, as bebidas alcóolicas (com destaque para a ) corresponderam, em média, a $20 \%$ das importações totais, o que é significativo, mas está longe do papel que parte da historiogafia lhe tem atribuído. ${ }^{7}$ Mariana Candido afirma que, após 1808, "os bens brasileiros dominaram o mercado de importações em Benguela" (p. 166), o que parece improvável, dado que, quando o parlamento britânico proibiu seus cidadãos de participar no comércio de escravos e o governo português abriu os portos brasileiros aos comerciantes das nações "amigas" de Portugal (como resultado das guerras napoleônicas), houve um grande fluxo de bens e capitais britânicos, assim como dos EUA, investidos no comércio de escravos para o Brasil. ${ }^{8}$

7 Ao leitor interessado em comparar com outros dados para o comércio de Angola, cf. Joseph C. Miller, "Imports at Luanda, Angola: 1785-1823", in Gerhard Liesegang, Helma Pasch e Adam Jones (orgs.), Figuring African Trade: Proceedings of the Symposium on the Quantification and Structure of the Import and Export and Long-Distance Trade of Africa in the Nineteenth Century (c. 1800-1913) (Berlin: D. Heimer, 1986), pp. 165-246; Gustavo Acioli Lopes e Maximiliano M. Menz, "Vestindo o escravismo: o comércio de têxteis e o Contrato de Angola (século XVIII)", , v. 39, n. 80 (2019), pp. 109-134.

8 Cf. Leonardo Marques, The United States 
Em suma, o leitor interessado nas ligações entre o tráfico transatlântico de escravos e a economia mundial pode encontrar informações úteis no livro de Domingues da Silva, embora ele e Mariana Candido pareçam superestimar o papel dos comerciantes "brasileiros" no financiamento e abastecimento de mercadorias em Angola e atribuam ênfase excessiva à abordagem a partir do Atlântico Sul.

and the Transatlantic Slave Trade to the Americas, 1776-1867, New Haven: Yale University Press, 2016; e Gerald Horne, O Sul mais distante: os Estados Unidos, o Brasil e o tráfico de escravos africanos, São Paulo: Companhia das Letras, 2010.
Apesar dessas observações, estes livros são importantes contribuições para o estudo do comércio transatlântico de escravos e das sociedades de onde se originavam. Eles restabelecem o debate sobre as atividades de escravização em Angola e suas consequências para seu povo. Ao ler essas obras, não se pode esquecer que a construção da economia moderna e suas conexões globais - incluindo o fluxo de metais preciosos, bens de luxo, manufaturas e commodities - se alicerçaram no processo desumano de escravização, no qual o tráfico português e, depois, o luso-brasileiro, desempenharam um papel fundamental.

Gustavo Acioli gustavo.acioli@ufrpe.br Universidade Federal Rural de Pernambuco 